\title{
Acceptability of Immunoprophylaxis and/or Chemoprophylaxis for Household Contacts of Patients with Hansen's Disease: A Prospective, Single-Center, Mixed Methods Study
}

\author{
Armi D.V. Espiridion-Calma, Belen L. Dofitas and Maria Elinor Grace Q. Sison \\ Department of Dermatology, College of Medicine and Philippine General Hospital, University of the Philippines Manila
}

\begin{abstract}
Objectives. Leprosy is an infectious disease affecting the skin and nerves caused by Mycobacterium leprae. Closer physical distance was found to increase risk transmission. Thus, targeted provision of prophylactic medications to household contacts of patients with leprosy could possibly aid in decreasing its incidence in a cost-effective manner. This study aimed to determine the attitudes towards disclosure of the diagnosis of leprosy and acceptance of immuno- and chemoprophylaxis for household contacts of patients undergoing treatment in a dermatology outpatient clinic of a tertiary hospital in the Philippines.
\end{abstract}

Methods. We conducted a prospective, single-center, cross-sectional and mixed methods study at a dermatology clinic of a tertiary hospital. All diagnosed leprosy patients, household contacts of leprosy patients, and individuals with no leprosy and no known contact with a leprosy case were invited. Eligible participants who gave consent were included in the cross-sectional survey, followed by in-depth interviews of selected participants. STATA 12 was used to analyze the data. Descriptive statistics were used to summarize information. Chi-square was computed to obtain a measure of association of important variables. The field notes and the verbatim transcriptions of the interviews and narratives were filed using an analytic memo system.

Results. Fifty-five participants (22 Hansen's disease patients, 13 household contacts, and 20 individuals unaffected by and unexposed to leprosy) were enrolled. Mean age of respondents was 38 years, $60 \%$ were female, and $85 \%$ were living in an urban setting. Majority of the patients with leprosy were borderline lepromatous (45\%) to lepromatous type (27\%) with mean treatment duration of 13 months. Overall, the respondents were willing to disclose the diagnosis of leprosy to their household members to facilitate provision of prophylaxis. They were also generally willing to receive prophylaxis despite potential side effects, expense, incomplete protection, and the need for yearly assessment for the development of leprosy. All respondents felt hopeful about the availability of medications that can prevent the development of leprosy and its complications, with some feeling anxious and only a few being embarrassed about receiving them.

Conclusions. Prophylactic medications were found to be generally acceptable despite some concerns. There is also a willingness to disclose the diagnosis of leprosy to facilitate the targeted provision of prophylaxis to household contacts.

Key Words: leprosy, post-exposure prophylaxis, attitude

\section{INTRODUCTION}

Corresponding author: Armi D.V Espiridion-Calma, MD

Department of Dermatology

Philippine General Hospital

University of the Philippines Manila

Taft Avenue, Manila 1000, Philippines

Email: armiespiridion@gmail.com
Leprosy is a chronic, slowly progressing, infectious disease affecting the skin and nerves caused by the bacillus, Mycobacterium leprae. Spread is thought to occur primarily through respiratory route; however, there is evidence that $M$. leprae can be shed through the skin and that it can possibly be transmitted through exposed skin surfaces. ${ }^{1}$ Incubation period is usually around 5 years, but can be up to 20 years in 
some cases. ${ }^{2}$ Leprosy causes significant disability in patients affected by it. The disability it causes is more than a mere physical dysfunction from nerve damage and skin lesions. It also includes stigma, discrimination, activity limitations, and social participation restrictions. ${ }^{3}$

Leprosy is not highly infectious. It has been found that closer physical distance of contacts from patients with leprosy increases their risk of contracting the disease. Other independent risk factors for transmission and development of clinical leprosy include the classification of leprosy of the index patient (multibacillary > paucibacillary), the age of the contact $(5-15$ years $<15-20$ years $>20-29$ years $<30$ years and above), and the genetic relationship (closer relationship > more distant relationship) of the contact to the patient. ${ }^{4}$

Recent evidences show that immunoprophylaxis with Bacille Calmette-Guerin (BCG) and/or chemoprophylaxis with antimycobacterial drugs of contacts of known leprosy patients can offer protection from the development of clinical disease, although it appears to be time-limited and less effective when given to more intimate contacts compared to contacts that are less close.

The elevated risk of disease transmission among close contacts of patients with leprosy and the ease by which they can be identified, makes them good candidates in a targeted approach for preventive measures such as immunoprophylaxis or chemoprophylaxis. Then again, even if many may appreciate the beneficial effects of these preventive measures, the leprosy patients can object to the disclosure of their diagnosis, which is a crucial step in the identification of contacts and delivery of targeted immunoprophylaxis and/or chemoprophylaxis, as leprosy is still a stigmatizing disease.

Official reports submitted to the World Health Organization (WHO) by 161 countries and territories for the year 2018 showed that the global prevalence of leprosy stood at 184,238 cases (prevalence rate of 0.24 per 10,000 population), while the number of new cases detected was 208,619 (case detection rate of 2.74 per 100,000 population). In the Philippines alone, the reported prevalence is 4,970 cases and the number of new cases detected is 2,176 cases at the end of $2018.89 .94 \%$ of the new cases are multibacillary (MB) cases while $2.34 \%$ have Grade-2 disabilities. ${ }^{5}$ In our institution, leprosy contributed to $0.27 \%(27 / 10,013)$ of the new consults in $2019 .^{6}$

The key elements in the WHO strategy for elimination of leprosy as a public health problem, defined as prevalence of less than 1 case per 10,000 populations, remain to be access to information, early detection of cases and treatment with multi-drug therapy (MDT). This goal has been achieved globally at the end of the year 2000. ${ }^{7}$ However, in some endemic countries, leprosy remains to be a significant public health problem.

Other methods are being looked at to enhance leprosy control. The Global Leprosy Strategy 2016-2020 listed early case detection, targeted detection among high risk groups, and screening of all close contacts as part of the five key strategic operational changes in further reducing the burden of leprosy in the global and local level. ${ }^{8}$ In 2018, the WHO Guidelines Development Group recommended the use of Single Dose Rifampicin (SDR) as post-exposure prophylaxis (PEP) for contacts of leprosy patients (adults and children 2 years of age and above), after excluding persons with leprosy, tuberculosis, as well as other contraindications. The requirements for the implementation of this recommendation by programmes include: "(i) adequate management of contacts and (ii) consent of the index case to disclose his/her disease (conditional recommendation, moderate quality evidence)." 9

BCG is part of the WHO's Expanded Programme on Immunization for protection against tuberculosis, which is caused by a mycobacterium closely related to $M$. leprae. Several studies have proven that it is also effective in protecting against leprosy, possibly due to immune cross reaction to shared antigens with $M$. leprae. Experimental studies show that $\mathrm{BCG}$ vaccination had an overall protective effect ranging from 26-43\% while observational studies (cohort and casecontrol studies) show a 58-62\% protection. ${ }^{10,11,12}$ Whether revaccination (second dose of BCG following a birth dose) offers an additional benefit is still uncertain since two large trials on BCG revaccination showed conflicting results. ${ }^{8}$ Another important finding from these studies was that BCG was more efficacious when used on household contacts (66\% protection) who are at higher risk of infection compared to the general population (56\% protection). ${ }^{12}$

A few trials have evaluated the role of chemoprophylaxis with different anti-mycobacterial drugs on leprosy prevention. Two systematic reviews and meta-analyses evaluating the effectiveness of chemoprophylaxis with different antimycobacterial drug regimens (single dose oral rifampicin, oral dapsone once or twice weekly for at least 2 years, and intramuscular acedapsone every 10 weeks for 7 months) showed that it was effective in preventing the occurrence of leprosy by up to $60 \% .{ }^{13,14}$ However, this effect is shown to be time-limited and less effective when given to more intimate contacts. Another systematic review showed that one dose of rifampicin reduced the incidence of leprosy among contacts of leprosy patients in the first two years by $56.5 \%$ and that this intervention is socially accepted. ${ }^{15}$

Individually, BCG vaccination and chemoprophylaxis have been shown to be effective strategies in preventing leprosy. A study, which assessed the combined effect of BCG vaccination and single dose rifampicin on leprosy prevention, showed that the protective effects provided by BCG vaccination and rifampicin, independently, were $57 \%$ and $58 \%$, respectively. But when these strategies were combined, the effect increased to $80 \%{ }^{16}$

Social acceptability studies done in other countries found that chemoprophylaxis for leprosy is well accepted. ${ }^{17,18}$ Results of focused group discussions among healthy individuals living in leprosy endemic areas of Bangladesh showed that the participants were willing to disclose the diagnosis to household members and nearby family but not 
to neighbors or other contacts if they were diagnosed with leprosy. They were also willing to take chemoprophylaxis even if full protection was not guaranteed. ${ }^{17}$ In India, contact screening and the introduction SDR as PEP in the Leprosy Post-Exposure Prophylaxis (LPEP) program also appeared to be well accepted by the main stakeholders (index patients, contacts, health workers and supervisors). Fear of disclosing the diagnosis of leprosy was not a barrier to the introduction of this intervention. ${ }^{18}$

In brief, despite effectiveness and availability of multidrug therapy, leprosy remains to be endemic in some countries. There is a constant search for safe and costeffective interventions that can be implemented to reduce disease burden. With evidence of increased risk in close contacts of diagnosed leprosy cases to contract the disease, targeting them for provision of preventive measures such as immunoprophylaxis and/or chemoprophylaxis could possibly contribute to the decline in incidence of the disease in a costeffective manner. However, in order to facilitate this targeted approach to preventing disease transmission, it is important to take into consideration the disposition of leprosy patients with regards to disclosing their diagnosis to their household contacts, which is an important initial step in this approach. It is also important to address the attitude and concerns of the household contacts towards taking these prophylactic medicines. Including healthy individuals with no known contact with leprosy in the study, as Feenstra et al did in Bangladesh, has the advantage of assessing the views and attitudes of individuals, who represent the community and are possible targets for prophylaxis in the future, with respect to leprosy and taking medications as prophylaxis.

This is the first study in the Philippines on the social acceptability of immunoprophylaxis and/or chemoprophylaxis for household contacts of diagnosed leprosy cases. Here, we determined the acceptability of targeted immunoprohylaxis and/or chemoprophylaxis for household contacts of confirmed leprosy cases undergoing treatment in a dermatology outpatient clinic of a tertiary hospital in the Philippines. Other outcomes assessed were willingness of the leprosy patients to disclose their diagnosis to household contacts, attitudes and perceptions of all respondents regarding prophylaxis for leprosy, and the potential barriers to its acceptability. This study aims to pave the way for further research and program development in leprosy prevention by identifying the facilitators and barriers to acceptability of prophylaxis for leprosy contacts.

\section{MATERIALS AND METHODS}

We conducted a prospective, single-center, cross-sectional and mixed methods study in a dermatology outpatient clinic of a tertiary hospital in the Philippines from February to November 2016.

The investigators developed a new questionnaire, the social acceptability of prophylaxis for household contacts of Filipino patients with leprosy questionnaire, composed of three (3) sections. Section 1 collected demographic data. Section 2 examined the participants' willingness to receive chemoprophylaxis and immunoprophylaxis. Section 3 assessed potential barriers to the use chemoprophylaxis and immunoprophylaxis for contacts of patients with leprosy, such as side-effects, cost, willingness to share diagnosis, undergoing assessment for leprosy. Questions were based on a previous acceptability study of pre-exposure prophylaxis for HIV among potential user groups but were tailored more for leprosy. ${ }^{19}$ These were translated to Filipino then back translated to English for content consistency. Pre-testing was done on 9 respondents to test questionnaire items' understandability and content validity.

Two new questionnaires for in-depth interviews were also developed to further investigate particulars about the attitudes and acceptance of prophylaxis for leprosy among respondents. These were also translated to Filipino then back translated to English until acceptable final translations were achieved. Pre-testing on 4 respondents was also done.

For the interviews, convenience sampling of respondents was done. We invited all 18-60 years old (1) confirmed leprosy patients, based on the WHO clinical criteria or histological findings of leprosy, (2) known household contact of diagnosed leprosy patients, and (3) individuals with no leprosy and no known contact with a leprosy patient, who consulted in our clinic. Participants who were unable to communicate verbally (i.e. due to illness, neuro-developmental problems, psychosis) and those who refused informed consent were excluded.

Eligible participants who gave consent were included in the survey done in a private area in the clinic. The first section of the questionnaire was self-administered, except for 1 participant who could neither read nor write, but could communicate verbally, while the last 2 sections were administered by one of the investigators. From each group of respondents, the investigators selected 3 respondents who were the most willing and 3 respondents who were the least willing to accept prophylaxis for leprosy. One-onone interviews were done in a private area in the clinic. The investigator took notes and digitally recorded the interview for documentation.

Data was encoded using Microsoft Excel software. STATA 12.0 was used for data analysis. Descriptive statistics was used to summarize the clinical characteristics of the patients. Frequency and proportion were used for nominal variables, median and range for ordinal variables, and mean and SD for interval/ratio variables. All valid data was included in the analysis. Missing variables was neither replaced nor estimated. Chi Square was computed to obtain a measure of association of important variables (demographic, socioeconomic, and disease characteristics) with the willingness to disclose the diagnosis of leprosy to household contacts (willing versus not willing) and the acceptability of providing chemoprophylaxis and/or immunoprophylaxis to household contacts (acceptable versus unacceptable). 
The field notes and the verbatim transcriptions of the interviews and narratives were filed using an analytic memo system. This involved the organization of data based on the concepts and themes that emerge from the data. The texts were read, significant words, phrases, sentences were highlighted, and key ideas that emerged were written and reflected upon.

The study was conducted in accordance with the guidelines of the Helsinki Declaration and was reviewed and approved by the hospital's ethics committee prior to its conduct.

\section{RESULTS}

\section{Participant characteristics}

We enrolled a total of 55 respondents. Twenty-two Hansen's disease patients, 13 household members of patients with Hansen's disease, and 20 individuals not affected by and had no known contact with a person with Hansen's disease participated in the cross-sectional survey. Only 13 out of 18 respondents, participated in the in-depth interviews. One invited participant was out of the country, while the rest were either unable to come back for the interview or were unreachable through the provided contact numbers. (Figure 1)

The average age of respondents was $38.36 \pm 11.23$ years, and $60 \%$ were female. Majority of the respondents were from Metro Manila (66\%). Only eight respondents were living in a rural setting. More than half were currently employed, and the patients had an average of two children, and household size of five persons. (Table 1)

The most common classification of leprosy disease among the participants with Hansen's disease was borderline lepromatous (45.45\%), followed by lepromatous (27.27\%). WHO disability grading were predominantly hands Grade 0 (59\%), feet Grade 1 (54.55\%), and eyes Grade 0 (54.55\%). Half of the patients had a Type 1 lepra reaction. The patients had been undergoing treatment for an average of 13 months.
Sixty-three percent of the patients felt discriminated. Ten of the 22 patients were PGH Hansen's Club members. (Table 2)

\section{Acceptance of and potential barriers to prophylaxis for Hansen's disease}

\section{Leprosy respondents}

Most patients with Hansen's disease would disclose their diagnosis to allow their household members to receive prophylaxis for the disease (63\% "definitely" and 27\% "probably") and would also recommend prophylaxis even if it did not offer full protection from the disease (63\% "yes, definitely" and 23\% "yes, probably"). All felt hopeful about the availability of prophylaxis for their household members (68\% "a lot of hope" and 32\% "some hope"). However, more than half of them still felt anxious (14\% "very anxious" and $41 \%$ "fairly anxious"), while some were embarrassed (36\% "fairly embarrassing") about the thought of their household members taking prophylaxis for leprosy. Majority were afraid that their household members will contract Hansen's disease (68\% definitely and 23\% probably) and would still allow their household members to take prophylaxis for leprosy even if they had to pay for it (50\% "definitely" and $41 \%$ "probably"), even if it caused side effects (41\% "definitely" and $18 \%$ "probably"), and even if their household members needed to undergo yearly assessment (73\% "definitely" and 18\% "probably). (Table 3)

In-depth interviews with patients with Hansen's disease showed that patients viewed leprosy as a disease affecting the skin and nerves manifesting as nodules, loss of sensation, and weakness, with a chance for improvement and cure. The possibility of contracting the disease as the immune response weakens was also mentioned. One respondent regarded leprosy as a dangerous and feared disease while another one perceived more awareness about the disease now.

Four out of five respondents were willing to allow their household members to receive prophylaxis to protect their loved ones, to stop the progression of the disease, and to

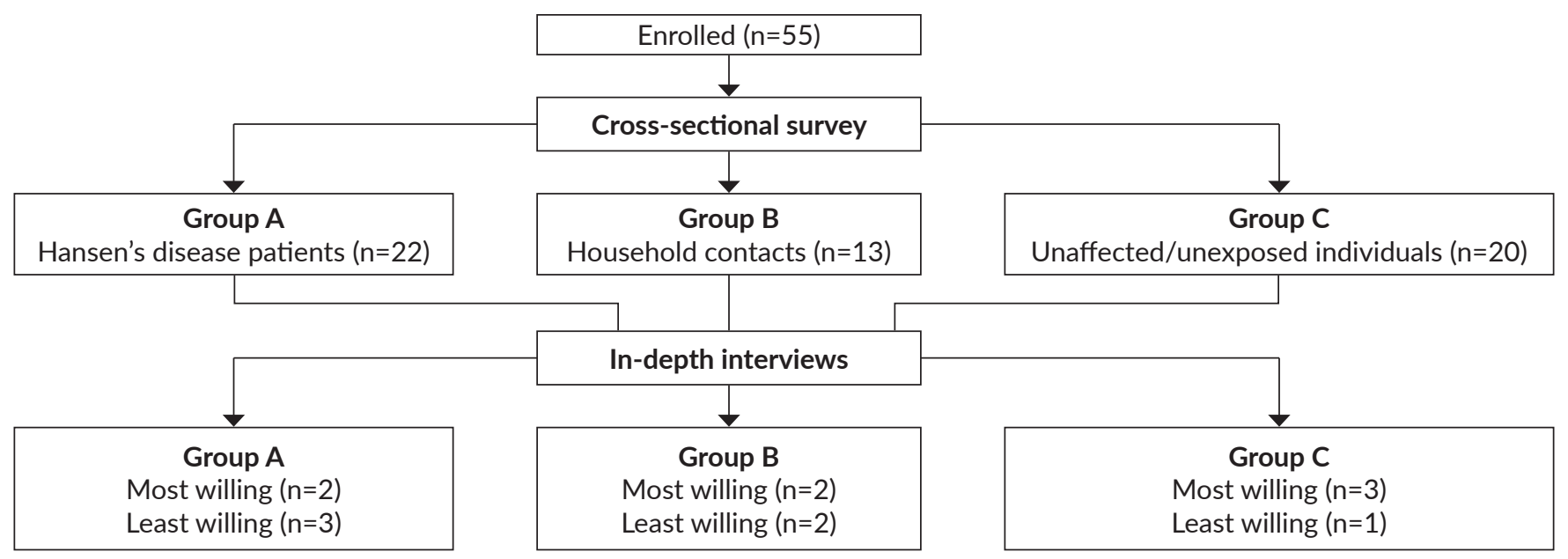

Figure 1. Study flow. 
Table 1. Demographic profile of respondents $(n=55)$

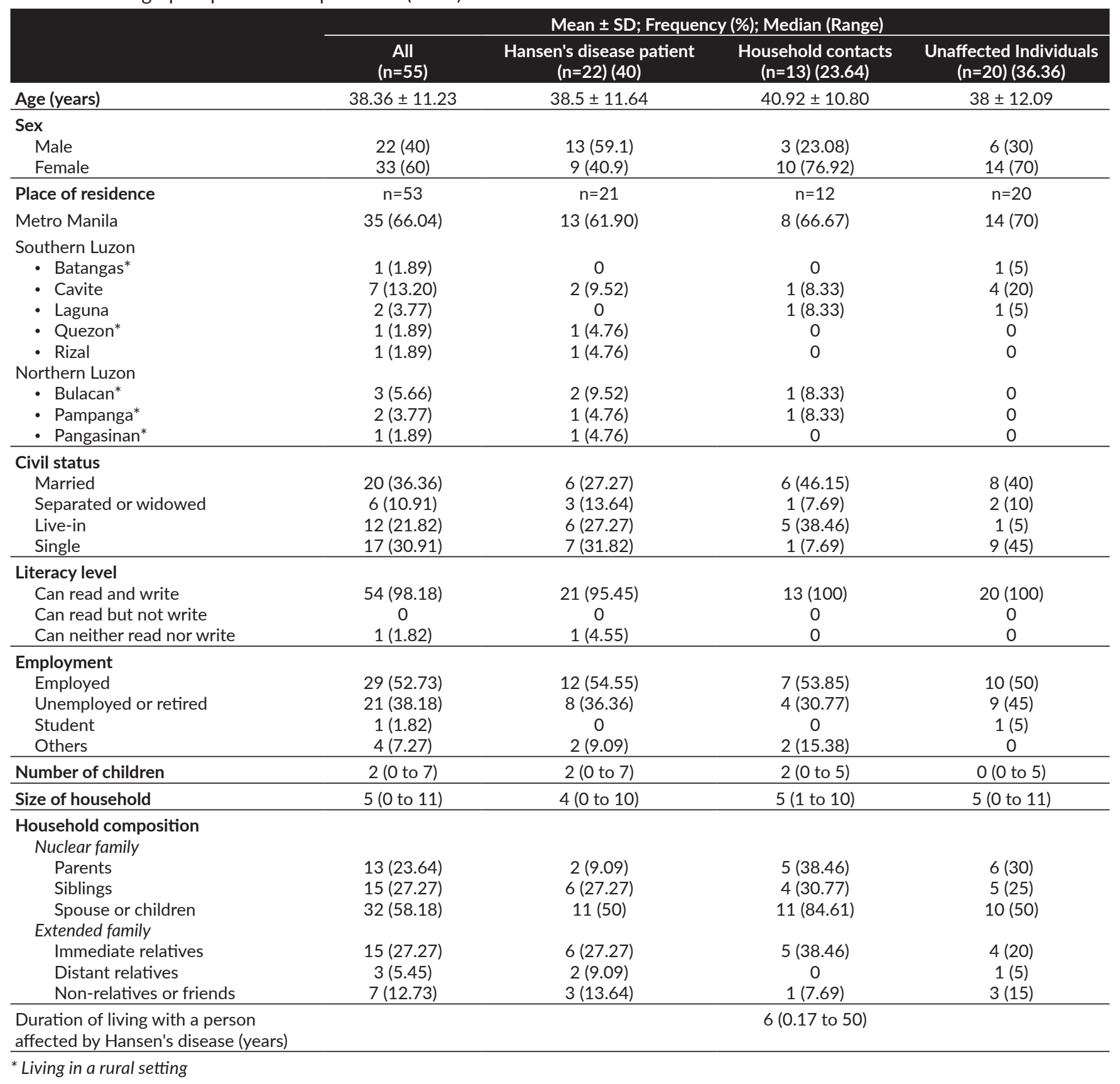

prevent them from experiencing the effects of the disease. The sole respondent who did not want her household members to receive prophylaxis felt that it was not needed because they have already accepted her and because she was embarrassed and afraid that knowledge of her disease might spread to others.

All were willing to disclose their diagnosis to their loved ones so that they will be more aware of the disease, to protect them, to control the progression of the disease, and to avoid disgust from others by informing them that there is a cure. One respondent was previously hesitant to disclose but is now willing to do so due to more knowledge about the disease.
All respondents had hope about the thought of having prophylaxis for their household contacts. Concerns regarding prophylaxis include the unfamiliarity of the medications, side effects, fear of household members contracting the disease, and the apprehension to disclose the diagnosis until the household contacts have fully understood the disease. Most will not be embarrassed by the thought of their household members receiving prophylaxis for leprosy. One was a bit embarrassed but knew the importance of preventing the disease, while one was totally embarrassed and would only disclose to people that she trusts. 
Table 2. Clinical profile of patients with Hansen's disease $(n=22)$

\begin{tabular}{|c|c|}
\hline & $\begin{array}{l}\text { Frequency (\%); } \\
\text { Median (Range) }\end{array}$ \\
\hline \multicolumn{2}{|l|}{ Classification of leprosy disease } \\
\hline \multicolumn{2}{|l|}{ Paucibacillary } \\
\hline TT / Tuberculoid & $2(9.09)$ \\
\hline BT / Borderline tuberculoid & $2(9.09)$ \\
\hline \multicolumn{2}{|l|}{ Multibacillary } \\
\hline BB / Midborderline or borderline & $2(9.09)$ \\
\hline BL / Borderline lepromatous & $10(45.45)$ \\
\hline LL / Lepromatous & $6(27.27)$ \\
\hline \multicolumn{2}{|l|}{$\begin{array}{l}\text { WHO disability grading } \\
\text { Hands* }\end{array}$} \\
\hline Grade 0 & $13(59.09)$ \\
\hline Grade 1 & $8(36.36)$ \\
\hline Grade 2 & $1(4.55)$ \\
\hline \multicolumn{2}{|l|}{ Feet* } \\
\hline Grade 0 & $10(45.45)$ \\
\hline Grade 1 & $12(54.55)$ \\
\hline Grade 2 & 0 \\
\hline \multicolumn{2}{|l|}{ Eyes $^{* *}$} \\
\hline Grade 0 & $12(54.55)$ \\
\hline Grade 1 & $9(40.91)$ \\
\hline Grade 2 & $1(4.55)$ \\
\hline \multicolumn{2}{|l|}{ Lepra reaction } \\
\hline None & $8(36.36)$ \\
\hline Type 1 & $11(50)$ \\
\hline Type 2 & $3(13.64)$ \\
\hline Duration of treatment (months) & 13 (0 to 96$)$ \\
\hline Felt discriminated due to illness & $13(63.64)$ \\
\hline PGH Hansen's Club member & $10(45.45)$ \\
\hline \multicolumn{2}{|c|}{$\begin{array}{l}\text { PGH, Philippine General Hospital. } \\
\text { * Hands and feet: Grade 0, no anesthesia, visible deformity, or damage; } \\
\text { Grade 1, anesthesia present but no visible deformity or damage; } \\
\text { Grade 2, visible deformity or damage present. } \\
\text { ** Eyes: Grade 0, no eye problem due to leprosy nor evidence of visual } \\
\text { loss; Grade 1, eye problems due to leprosy present but vision not } \\
\text { severely affected as a result of these [vision: } 6 / 60 \text { or better; can } \\
\text { count fingers at } 6 \mathrm{~m} \text { ]; Grade 2, severe visual impairment [vision: } \\
\text { worse than 6/60; inability to count fingers at } 6 \mathrm{~m} \text { ] also includes } \\
\text { lagophthalmos, iridocyclitis, and corneal opacities. }\end{array}$} \\
\hline
\end{tabular}

The fear of household members contracting Hansen's disease was shared by all respondents because they were afraid that their loved ones would experience the difficulties they went through, that it will destroy their lives, and that they will be loathed by people who are not aware of the disease. Similar to the responses in the survey questionnaire, most would allow their household members to take prophylaxis despite having to pay for it, if their budget will allow, to promote health and to avoid additional costs for treatment. Four out of the five respondents would also allow their household contacts to receive prophylaxis despite side effects only if the side were explained if it can be managed by the physician and if it is acceptable to the household members themselves. All but one would also allow their household contacts to receive prophylaxis despite the need for yearly assessment for the development of Hansen's disease. The only respondent who would not allow it did not want to inconvenience her household members.
Table 3. Attitudes of patients affected with Hansen's disease towards prophylaxis for their household members $(n=22)$

\begin{tabular}{|c|c|}
\hline & Frequency (\%) \\
\hline $\begin{array}{l}\text { Willingness to disclose diagnosis } \\
\text { Definitely } \\
\text { Probably } \\
\text { Probably not } \\
\text { Definitely not } \\
\end{array}$ & $\begin{array}{c}14(63.64) \\
6(27.27) \\
1(4.45) \\
1(4.45) \\
\end{array}$ \\
\hline $\begin{array}{l}\text { Despite incomplete protection } \\
\text { Yes, definitely } \\
\text { Yes, probably } \\
\text { No, probably not } \\
\text { No, definitely not } \\
\end{array}$ & $\begin{array}{c}14(63.64) \\
5(22.73) \\
2(9.09) \\
1(4.55) \\
\end{array}$ \\
\hline $\begin{array}{l}\text { Hope } \\
\text { A lot of hope } \\
\text { Some hope } \\
\text { Not much hope } \\
\text { No hope }\end{array}$ & $\begin{array}{c}15 \text { (68.18) } \\
7(31.82) \\
0 \\
0\end{array}$ \\
\hline $\begin{array}{l}\text { Anxiety } \\
\text { Not at all anxious } \\
\text { Not very anxious } \\
\text { Fairly anxious } \\
\text { Very anxious } \\
\end{array}$ & $\begin{array}{l}4(18.18) \\
6(27.27) \\
9(40.91) \\
3(13.64) \\
\end{array}$ \\
\hline $\begin{array}{l}\text { Embarrassment } \\
\text { Not at all embarrassing } \\
\text { Not very embarrassing } \\
\text { Fairly embarrassing } \\
\text { Very embarrassing } \\
\end{array}$ & $\begin{array}{c}10(45.45) \\
4(18.18) \\
8(36.36) \\
0 \\
\end{array}$ \\
\hline $\begin{array}{l}\text { Fear of household members contracting leprosy } \\
\text { Very afraid } \\
\text { Fairly afraid } \\
\text { Not very afraid } \\
\text { Not at all afraid } \\
\end{array}$ & $\begin{array}{c}15(68.18) \\
5(22.73) \\
0 \\
2(9.09) \\
\end{array}$ \\
\hline $\begin{array}{l}\text { Despite having to pay } \\
\text { Definitely } \\
\text { Probably } \\
\text { Probably not } \\
\text { Definitely not }\end{array}$ & $\begin{array}{c}11(50) \\
9(40.91) \\
1(4.55) \\
1(4.55)\end{array}$ \\
\hline $\begin{array}{l}\text { Despite side-effects } \\
\text { Definitely } \\
\text { Probably } \\
\text { Probably not } \\
\text { Definitely not } \\
\end{array}$ & $\begin{array}{c}9(40.91) \\
4(18.18) \\
8(36.36) \\
1(4.55) \\
\end{array}$ \\
\hline $\begin{array}{l}\text { Despite yearly assessment for leprosy } \\
\text { Definitely } \\
\text { Probably } \\
\text { Probably not } \\
\text { Definitely not }\end{array}$ & $\begin{array}{c}16(72.73) \\
4(18.18) \\
2(9.09) \\
0\end{array}$ \\
\hline
\end{tabular}

Efficacy is the main feature of a medication that can encourage respondents to allow their household contacts to receive prophylaxis, while the refusal of household contacts, possible ill effects of the medications to the body, and lack of funds could prevent them from doing the same.

\section{Household contact respondents}

Results of the survey conducted on household contacts of patients with Hansen's disease and individuals unaffected by and had no known contact with Hansen's disease showed a fairly similar trend as the responses of the patients with Hansen's disease. Majority were willing to accept prophylaxis 
Table 4. Acceptability of prophylactic treatments for Hansen's disease $(n=33)$

\begin{tabular}{|c|c|c|}
\hline & $\begin{array}{c}\text { Household } \\
\text { contact of a } \\
\text { person with } \\
\text { Hansen's } \\
\text { disease } \\
(\mathrm{n}=13)\end{array}$ & $\begin{array}{l}\text { Not affected } \\
\text { and not in } \\
\text { contact with } \\
\text { a person with } \\
\text { Hansen's } \\
\text { disease }(n=20) \\
\end{array}$ \\
\hline & \multicolumn{2}{|c|}{ Frequency (\%) } \\
\hline $\begin{array}{l}\text { Willingness to receive prophylaxis } \\
\text { Definitely } \\
\text { Probably } \\
\text { Probably not } \\
\text { Definitely not }\end{array}$ & $\begin{array}{c}10(76.92) \\
2(15.38) \\
1(7.69) \\
0\end{array}$ & $\begin{array}{c}16(80) \\
3(15) \\
1(5) \\
0\end{array}$ \\
\hline $\begin{array}{l}\text { Despite incomplete protection } \\
\text { Definitely } \\
\text { Probably } \\
\text { Probably not } \\
\text { Definitely not } \\
\end{array}$ & $\begin{array}{c}8(61.54) \\
4(30.77) \\
1(7.69) \\
0 \\
\end{array}$ & $\begin{array}{c}12(60) \\
7(35) \\
1(5) \\
0\end{array}$ \\
\hline $\begin{array}{l}\text { Hope } \\
\text { A lot of hope } \\
\text { Some hope } \\
\text { Not much hope } \\
\text { No hope }\end{array}$ & $\begin{array}{c}12 \text { (92.31) } \\
1 \text { (7.69) } \\
0 \\
0 \\
\end{array}$ & $\begin{array}{c}15(75) \\
5(25) \\
0 \\
0\end{array}$ \\
\hline $\begin{array}{l}\text { Anxiety } \\
\text { Not at all anxious } \\
\text { Not very anxious } \\
\text { Fairly anxious } \\
\text { Very anxious } \\
\end{array}$ & $\begin{array}{c}3(23.08) \\
2(15.38) \\
8(61.54) \\
0\end{array}$ & $\begin{array}{c}5(25) \\
5(25) \\
10(50) \\
0 \\
\end{array}$ \\
\hline $\begin{array}{l}\text { Embarrasment } \\
\text { Not at all embarrassing } \\
\text { Not very embarrassing } \\
\text { Fairly embarrassing } \\
\text { Very embarrassing }\end{array}$ & $\begin{array}{c}8(61.54) \\
1(7.69) \\
4(30.77) \\
0\end{array}$ & $\begin{array}{c}8(40) \\
5(25) \\
6(30) \\
1(5)\end{array}$ \\
\hline $\begin{array}{l}\text { Fear of contracting Hansen's disease } \\
\text { Very afraid } \\
\text { Fairly afraid } \\
\text { Not very afraid } \\
\text { Not at all afraid }\end{array}$ & $\begin{array}{c}7(53.85) \\
4(30.77) \\
0 \\
2(15.38)\end{array}$ & $\begin{array}{c}15(75) \\
3(15) \\
1(5) \\
1(5)\end{array}$ \\
\hline
\end{tabular}

(79\% "definitely" and 15\% "probably") and still willing to accept it even if it did not offer full protection $(61 \%$ "definitely" and 33\% "probably"). All were hopeful about prophylaxis (82\% "a lot of hope" and 18\% "some hope"). Similar to the responses by the patients with Hansen's disease, more than half of the respondents from both groups were anxious (55\% "fairly anxious") and some were embarrassed (3\% "very embarrassed" and 30\% "fairly embarrassed") at the thought of taking prophylaxis for leprosy. Once more, most of the respondents were afraid to contract Hansen's disease (67\% "very afraid" and 21\% "fairly afraid") and would still take prophylaxis despite having to pay for it ( $42 \%$ "definitely" and 36\% "probably"), despite side effects (27\% "definitely" and 30\% "probably"), and despite yearly assessment for the development of Hansen's disease (67\% "definitely" and 30\% "probably"). All respondents were willing to disclose the diagnosis of Hansen's disease to their household contacts. (Tables 4 and 5)

In the in-depth interviews, 3 of the 4 household contacts of patients with Hansen's disease, who were interviewed,
Table 5. Potential barriers to the acceptability of prophylactic treatments for Hansen's disease $(n=33)$

\begin{tabular}{lcc} 
& $\begin{array}{c}\text { Household } \\
\text { contact of a } \\
\text { person with } \\
\text { Hansen's } \\
\text { disease } \\
\text { (n=13) }\end{array}$ & $\begin{array}{c}\text { Not affected } \\
\text { and not in } \\
\text { contact with } \\
\text { a person with } \\
\text { Hansen's } \\
\text { disease (n=20) }\end{array}$ \\
\cline { 2 - 3 } & \multicolumn{2}{c}{ Frequency (\%) } \\
Willingness to disclose & \multicolumn{2}{c}{} \\
Definitely & $8(61.54)$ & $15(80)$ \\
Probably & $5(38.46)$ & $4(20)$ \\
Probably not & 0 & 0 \\
Definitely not & 0 & 0 \\
\hline Despite having to pay & \multicolumn{3}{c}{0} \\
Definitely & $6(46.15)$ & $8(40)$ \\
Probably & $4(30.77)$ & $8(40)$ \\
Probably not & $3(23.08)$ & $4(20)$ \\
Definitely not & 0 & 0 \\
\hline Despite side effects & & \\
Definitely & $1(7.69)$ & $8(40)$ \\
Probably & $4(30.77)$ & $6(30)$ \\
Probably not & $6(46.15)$ & $5(25)$ \\
Definitely not & $2(15.38)$ & $1(5)$ \\
\hline Despite yearly assessment for leprosy & & \\
Definitely & $7(53.85)$ & $15(75)$ \\
Probably & $6(46.15)$ & $4(20)$ \\
Probably not & 0 & $1(5)$ \\
Definitely not & 0 & 0 \\
\hline
\end{tabular}

regarded the disease as a disease affecting the skin. One knew that it was an infectious disease, however, she thought that it could be transmitted through contact with contaminated water, dirt, fomites, and people. Many of them will accept prophylaxis to be protected and prevent the spread of the disease but one will not accept if he has no active disease. All of them would disclose the diagnosis of Hansen's to household members, should they have Hansen's disease, to facilitate awareness and protection, prevent the spread of the disease, and prevent people from loathing them.

All had hope due to the assistance given and the availability of medications and were not embarrassed at the thought of receiving prophylaxis for leprosy. However, they still expressed concerns regarding possible expenses for the prophylaxis, length of treatment, and effects of medications.

Only one of the respondents was not afraid to contract Hansen's disease because the cure is already available. Others were afraid because of concerns of possible spread to family members, acceptance of people around them, and a decrease in productivity due to the illness. However, only one would definitely accept prophylaxis despite having to pay for it as long as it was effective. The others would only accept prophylaxis if their budget allowed it. In contrast, all but one would accept prophylaxis despite having side effects if there is a prescription, if other drugs can replace the medication if it had side effects, or if side effects are treatable; and despite having to undergo a yearly assessment to monitor and prevent disease activity and to prevent spread to family members. 
Efficacy of protection, absent or minimal side effects and drug interactions, and brand of the medication are the features that would encourage the respondents to receive prophylaxis for Hansen's disease, while prolonged daily intake of the medication, presence of side effects, and delivery methods (injections) would prevent them from doing so.

\section{Respondents not affected by leprosy}

Individuals unaffected by leprosy and who have no known contact to patients with Hansen's disease generally regard leprosy as a skin disease that is contagious. However, one respondent mistook leprosy for leptospirosis, which is a disease spread by rats, and only had knowledge of superstitions about the disease. All respondents were willing to accept prophylaxis for leprosy generally for protection, as one of them expressed that he may not be able to accept having the disease. All of them were also willing to disclose their diagnosis to their household members to increase their awareness about the disease and to get support and help. One respondent even likened the diagnosis of Hansen's disease to HIV, which according to him necessitates the support of family members.

All respondents have hope about the thought of the availability of prophylaxis for Hansen's disease because it gives them confidence that there are cure and protection from the disease. Side effects and incomplete cure are the concerns regarding receiving prophylaxis. Embarrassment was not an issue in this group of respondents as well.

Fear of contracting Hansen's disease was shared by all respondents because of the fear that there is no cure, feeling of shame due to stigma, and the fear of having the disease itself. Only one respondent will not accept prophylaxis if he had to pay for it, the others would still accept it if their budget permits, to prevent the disease. The same respondent also would not accept prophylaxis if it caused side effects. He would rather stay away from a relative who has the disease to protect himself rather than take medications with side effects, especially if he has good health prior to giving the medications. He was also the only one who did not want to undergo yearly assessment for the development of leprosy because he would rather not know if he had the disease.

Free and effective medications for prophylaxis were the preferred features of medications by this group of respondents, while the features that would negatively affect their decision to accept the medications were if it had harmful effects to the body and if it is not yet proven to effectively cure the disease.

Association of demographic, socioeconomic, disease characteristics with the willingness to disclose the diagnosis among Hansen's disease patients

There was no significant association relating age (1830 vs. $31-40$ vs. $41-50$ vs. $51-60$ ), gender (male vs. female), place of residence (urban vs. rural), employment status (with source of income vs. without source of income), classification of leprosy (TT vs. BT vs. BB vs. BL vs. LL), presence of disability (with vs. without), presence of lepra reaction (with vs. without), and the duration of treatment (less than one year vs. more than one year), with the willingness to disclose the diagnosis of leprosy to household members (willing vs. not willing) found among the patients with Hansen's disease who participated in this study. (Table 6)

\section{Association of demographic, and socioeconomic characteristics with acceptance of prophylaxis}

No significant association was also seen linking age (1830 vs. $31-40$ vs. $41-50$ vs. $51-60$ ), gender (male vs. female), place of residence (urban vs. rural), and employment status (with source of income vs. without source of income), with the acceptance of prophylaxis among household members of patients with Hansen's disease and individuals with no exposure to Hansen's disease. (Table 7)

\section{DISCUSSION}

Results showed an overall positive attitude towards disclosing the diagnosis of leprosy to household contacts among the respondents, Hansen's disease patients and individuals who do not have the disease alike. The willingness stemmed from the desire to promote awareness among other people who might have limited knowledge about this disease, to facilitate the protection of loved ones from contracting the disease with the provision of prophylactic medications, to prevent further spread of the disease, and ultimately to stop the burden associated with the disease, such as disability, discrimination, and stigma. Knowledge of the willingness to the disclosure of the diagnosis of leprosy opens many windows of opportunity and is a key step in the institution of strategies for further reducing the burden of leprosy. Disclosure of the diagnosis will facilitate the identification of contacts that are at increased risk of contracting the disease, enabling the focused approach to screening that can lead to early detection of and early institution of treatment with multi-drug therapy and also, possibly, the provision of medications for prophylaxis, which is a promising added approach to stopping the development and preventing the spread of Hansen's disease.

A positive attitude towards the acceptance of medicines for prophylaxis was also seen in this study. This signifies the desire of the respondents to overcome the disease despite the presence of certain barriers or concerns surrounding the use of these prophylactic treatments. Our results parallel the findings by Feenstra et al. and Apte et al., which also revealed willingness of the participants to accept prophylactic treatments and to disclose the diagnosis of leprosy among household members and nearby relatives. ${ }^{17,18}$ However, the difference in our methodologies, such as the groups involved (index patients, contacts, healthy individuals, key informants, health workers), as well as the nature of collecting 
Table 6. Measure of association between demographic, socioeconomic, and disease characteristics with willingness to disclose the diagnosis of leprosy among patients with Hansen's disease

\begin{tabular}{|c|c|c|c|c|c|}
\hline \multicolumn{6}{|c|}{ Age group and willingness to disclose diagnosis } \\
\hline & & $18-30 \%(n=6)$ & $31-40 \%(n=6)$ & $41-50 \%(n=7)$ & $51-60 \%(n=3)$ \\
\hline Willing to disclose & & 100.0 & 66.7 & 85.7 & 100.0 \\
\hline Not willing to disclose & & 0.0 & 33.3 & 14.3 & 0.0 \\
\hline \multicolumn{6}{|c|}{$x 2=3.400$ P-value $=0.334$} \\
\hline \multicolumn{6}{|c|}{ Gender and willingness to disclose diagnosis } \\
\hline & & \multicolumn{2}{|l|}{ Male \% (n=13) } & \multicolumn{2}{|l|}{ Female $\%(n=8)$} \\
\hline Willing to disclose & & \multicolumn{2}{|l|}{84.6} & \multicolumn{2}{|l|}{88.9} \\
\hline \multirow{2}{*}{\multicolumn{2}{|c|}{ Not willing to disclose }} & 15.4 & & 11.1 & \\
\hline & & \multicolumn{4}{|c|}{$x 2=0.082$ P-value $=0.774$} \\
\hline \multicolumn{6}{|c|}{ Residence and willingness to disclose diagnosis } \\
\hline & & \multicolumn{2}{|l|}{ Urban \% $(n=13)$} & \multicolumn{2}{|l|}{ Rural \% (n=8) } \\
\hline \multicolumn{2}{|l|}{ Willing to disclose } & \multicolumn{2}{|l|}{84.6} & \multicolumn{2}{|l|}{100} \\
\hline \multirow{2}{*}{\multicolumn{2}{|c|}{ Not willing to disclose }} & 15.4 & & \multicolumn{2}{|l|}{0} \\
\hline & & \multicolumn{2}{|c|}{$\mathrm{x} 2=1.360$ P-value $=0.243$} & & \\
\hline \multicolumn{6}{|c|}{ Employment status and willingness to receive prophylaxis } \\
\hline & & \multicolumn{2}{|c|}{ With source of income\% (n=14) } & \multicolumn{2}{|c|}{ Without source of income $\%(n=8)$} \\
\hline \multirow{3}{*}{\multicolumn{2}{|c|}{ Not willing to disclose }} & \multicolumn{2}{|c|}{85.7} & \multicolumn{2}{|c|}{100} \\
\hline & & \multicolumn{2}{|l|}{14.3} & \multicolumn{2}{|l|}{0} \\
\hline & & $x 2=1.257$ P-va & $=0.262$ & & \\
\hline Classification of leprosy & ss to disclose & & & & \\
\hline & TT \% (n=2) & BT \% (n=2) & $\mathrm{BB} \%(\mathrm{n}=2)$ & $B L \%(n=10)$ & $\operatorname{LL} \%(n=6)$ \\
\hline Willing to disclose & 100 & 100 & 100 & 90 & 83.3 \\
\hline Not willing to disclose & 0 & 0 & 0 & 10 & 16.7 \\
\hline & & $x 2=1.027$ P-va & $=0.906$ & & \\
\hline Presence of disability ar & to disclose di & & & & \\
\hline & & With disability 9 & $=14)$ & Without disabi & $6(n=8)$ \\
\hline Willing to disclose & & 82.4 & & 100.0 & \\
\hline Not willing to disclose & & 17.6 & & 0.0 & \\
\hline & & $\mathrm{x} 2=1.022 \mathrm{P}-\mathrm{va}$ & $=0.312$ & & \\
\hline Presence of lepra reacti & ness to disclo & & & & \\
\hline & & With lepra react & $\%(n=14)$ & Without lepra r & ion \% $(n=8)$ \\
\hline Willing to disclose & & 100 & & 75 & \\
\hline Not willing to disclose & & 0 & & 25 & \\
\hline & & $\mathrm{x} 2=3.85$ P-valu & 0.050 & & \\
\hline Duration of treatment $f$ & villingness to & liagnosis & & & \\
\hline & & Less than 1 year & $(n=10)$ & More than 1 ye & $(n=12)$ \\
\hline Willing to disclose & & 90.0 & & 91.7 & \\
\hline Not willing to disclose & & 10 & & 8.3 & \\
\hline & & $x 2=0.0183 P-v$ & $e=0.892$ & & \\
\hline
\end{tabular}

data (focused group discussions versus survey and in-depth interviews), may not permit precise comparisons between the results of our studies.

The positive attitude to prophylaxis among the respondents may be explained by the hope the medications for prophylaxis offers to protect from the development of Hansen's disease, prevent its spread within the family and to others, and end stigma and shame associated with this disease. Another source of motivation towards acceptance is probably the fear of physical dysfunction, leading to limitation of activity and decreased productivity, stigma, and discrimination associated with the disease. These were the recurring themes that were recognized during the in-depth interviews.

Possible side effects of the medications, expenses, incomplete protection, and concerns about adherence to clinical assessments could still affect the attitude towards acceptance among those who are being targeted for prophylaxis. Hence, it is important to address these concerns prior to forming strategies to facilitate distribution of prophylaxis as part the preventive approaches to leprosy and its complications. 
Table 7. Measure of association between demographic, and socioeconomic characteristics with willingness to prophylaxis for leprosy among household contacts of patients with Hansen's disease and individuals not affected by Hansen's disease

\begin{tabular}{|c|c|c|c|c|}
\hline \multicolumn{5}{|c|}{ Age group and willingness to disclose diagnosis } \\
\hline & $18-30 \%(n=10)$ & $31-40 \%(n=9)$ & $41-50 \%(n=10)$ & $51-60 \%(n=4)$ \\
\hline Willing to disclose & 100.0 & 88.9 & 90.0 & 75.0 \\
\hline \multirow[t]{2}{*}{ Not willing to disclose } & 0.0 & 11.1 & 10.0 & 25.0 \\
\hline & \multicolumn{4}{|c|}{$\mathrm{x} 2=3.400 \mathrm{P}$-value $=0.334$} \\
\hline \multicolumn{5}{|c|}{ Gender and willingness to receive prophylaxis } \\
\hline & \multicolumn{2}{|l|}{ Male \% $(n=9)$} & \multicolumn{2}{|l|}{ Female $\%(n=24)$} \\
\hline Willing to accept & \multicolumn{2}{|l|}{88.9} & \multicolumn{2}{|l|}{95.8} \\
\hline \multirow[t]{2}{*}{ Not willing to accept } & 11.1 & & 4.2 & \\
\hline & \multicolumn{4}{|c|}{$\chi 2=0.554$ P-value $=0.457$} \\
\hline \multicolumn{5}{|c|}{ Residence and willingness to receive prophylaxis } \\
\hline & \multicolumn{2}{|l|}{ Urban \% ( $n=22)$} & \multicolumn{2}{|l|}{ Rural \% (n=10) } \\
\hline Willing to accept & \multicolumn{2}{|l|}{95.5} & \multicolumn{2}{|l|}{90.0} \\
\hline \multirow[t]{2}{*}{ Not willing to accept } & 4.5 & & 10.0 & \\
\hline & \multicolumn{4}{|c|}{$\chi 2=0.349$ P-value $=0.555$} \\
\hline \multicolumn{5}{|c|}{ Employment status and willingness to receive prophylaxis } \\
\hline & \multicolumn{2}{|c|}{ With source of income\% $(n=18)$} & \multicolumn{2}{|c|}{ Without source of income $\%(n=15)$} \\
\hline Willing to accept & \multicolumn{2}{|c|}{100} & \multicolumn{2}{|c|}{86.7} \\
\hline \multirow[t]{2}{*}{ Not willing to accept } & 0 & & 13.3 & \\
\hline & \multicolumn{4}{|c|}{$\chi 2=2.555$ P-value $=0.110$} \\
\hline
\end{tabular}

The non-random selection of our respondents was a limitation of this study. Despite our efforts to ensure that different demographic and socioeconomic backgrounds were represented, most respondents still came from urban areas, hence, findings may not be generalizable to the rural settings. The small number of respondents could also have limited the detection of significant associations between variables and the outcomes of interests in this study. Lastly, since we were investigating a sensitive topic, there was a risk that respondents would answer questions in a manner that they deemed would be viewed favorably by others.

\section{CONCLUSIONS AND RECOMMENDATIONS}

We have shown that the patients in our health institution would be willing to take prophylactic medications for leprosy and disclose the diagnosis of leprosy to their household members in order to facilitate the provision of these medications to them despite some concerns. Side effects, expense, incomplete protection, and adherence are concerns that must be overcome in the implementation of this strategy in leprosy control and prevention programs.

Although medicines for leprosy post-exposure prophylaxis was deemed acceptable, as shown in this study, it is still important for the physician to completely educate the patients and their household contacts about the benefits and advantages of these medications to help dissipate their concerns.

Further studies to validate the efficacy and safety of these treatments may be done to address concerns about the medications' efficacy and adverse events. Cost-effectiveness analysis may also be conducted to guide policy makers in planning strategies to include these treatments in the implementation of prevention programs. A study on a larger sample of respondents may also be done in the future and may include in the methodology, the analysis of the association of willingness to disclose the diagnosis of leprosy and the acceptability of prophylaxis with the membership to a support group.

Lastly, the specific attitudes and concerns of potential users must be taken into consideration in adding prophylactic treatments for leprosy in prevention programs. Offering these treatments for free and making them available in different healthcare facilities may help alleviate financial concerns and improve adherence.

\section{Acknowledgments}

We are grateful to all the participants of this study who shared with us some of their valuable time.

\section{Statement of Authorship}

All authors participated in data collection and analysis, and approved the final version submitted.

\section{Author Disclosure}

All authors declared no conflicts of interest.

\section{Funding Source}

This study was partially funded by the World Health Organization Western Pacific Regional Office. 


\section{REFERENCES}

1. Job CK, Jayakumar J, Kearney M, Gillis TP. Transmission of leprosy: a study of skin and nasal secretions of household contacts of leprosy patients using PCR. Am J Trop Med Hyg. 2008; 78(3):518-21.

2. World Health Organization. Leprosy [Internet]. 2016 [cited 2016 Dec]. Available from: http://www.who.int/mediacentre/factsheets/ fs101/en/\#.WEN_9HmwC6w

3. van Brakel WH, Sihombing B, Djarir H, Beise K, Kusumawardhani L, Yulihane R, et al. Disability in people affected by leprosy: the role of impairment, activity, social participation, stigma and discrimination. Glob Health Action. 2012;5 doi:10.3402/gha.v5i0.18394.

4. Moet FJ, Pahan D, Schuring RP, Oskam L, Richardus JH. Physical distance, genetic relationship, age, and leprosy classification are independent risk factors for leprosy in contacts of patients with leprosy. J Infect Dis. 2006; 193(3):346-53.

5. World Health Organization. Global leprosy update, 2018: moving towards a leprosy-free world. Wkly Epidemiol Rec. 2019; 94(35/36):389-412.

6. Obbus SFV. Annual Report 2019. Department of Dermatology, University of the Philippines - Philippine General Hospital. 2019 Dec.

7. Pannikar V. Enhanced global strategy for further reducing the disease burden due to leprosy: 2011-2015. Lepr Rev. 2009; 80(4):353-4.

8. Regional Office for South-East Asia, World Health Organization. Global Leprosy Strategy 2016-2020: Accelerating towards a leprosyfree world. 2016

9. New Delhi: World Health Organization, Regional Office for SouthEast Asia. Guidelines for the diagnosis, treatment and prevention of leprosy. 2017

10. Setia MS, Steinmaus C, Ho CS, Rutherford GW. The role of BCG in prevention of leprosy: a meta-analysis. Lancet Infect Dis. 2006; 6(3):162-70.
11. Zodpey SP. Protective effect of bacillus Calmette Guerin (BCG) vaccine in the prevention of leprosy: a meta-analysis. Indian J Dermatol Venereol Leprol. 2007; 73(2):86-93.

12. Merle CS, Cunha SS, Rodrigues LC. BCG vaccination and leprosy protection: review of current evidence and status of BCG in leprosy control. Expert Rev Vaccines. 2010; 9(2):209-22.

13. Smith CM, Smith WC. Chemoprophylaxis is effective in the prevention of leprosy in endemic countries: a systematic review and meta-analysis. MILEP2 Study Group. Mucosal Immunology of Leprosy. J Infect. 2000; 41(2):137-42.

14. Reveiz L, Buendía JA, Téllez D. Chemoprophylaxis in contacts of patients with leprosy: systematic review and meta-analysis. Rev Panam Salud Publica. 2009; 26(4):341-9.

15. Ferreira SMB, Yonekura T, Ignotti E, de Oliveira LB, Takahashi J, Soares CB. Effectiveness of rifampicin chemoprophylaxis in preventing leprosy in patient contacts: a systematic review of quantitative and qualitative evidence. JBI Database System Rev Implement Rep. 2017; 15(10):2555-84.

16. Schuring RP, Richardus JH, Pahan D, Oskam L. Protective effect of the combination $\mathrm{BCG}$ vaccination and rifampicin prophylaxis in leprosy prevention. Vaccine. 2009; 27(50):7125-8.

17. Feenstra SG, Nahar Q, Pahan D, Oskam L, Richardus JH. Acceptability of chemoprophylaxis for household contacts of leprosy patients in Bangladesh: a qualitative study. Lepr Rev. 2011; 82(2):178-87.

18. Apte H, Chitale M, Das S, Manglani P, Mieras L. Acceptability of contact screening and single dose rifampicin as chemoprophylaxis for leprosy in Dadra and Nagar Haveli, India. Lepr Rev. 2019;90(1):31-45.

19. Eisingerich AB, Wheelock A, Gomez GB, Garnett GP, Dybul MR, Piot PK. Attitudes and acceptance of oral and parenteral HIV preexposure prophylaxis among potential user groups: a multinational study. PloS One. 2012; 7(1):e28238. 